\title{
Economic Evaluations of Occupational Health Interventions from a Company's Perspective: A Systematic Review of Methods to Estimate the Cost of Health-Related Productivity Loss
}

\author{
Kimi Uegaki • Martine C. de Bruijne • \\ Allard J. van der Beek • Willem van Mechelen • \\ Maurits W. van Tulder
}

Published online: 29 July 2010

(C) The Author(s) 2010. This article is published with open access at Springerlink.com

\begin{abstract}
Objectives: To investigate the methods used to estimate the indirect costs of health-related productivity in economic evaluations from a company's perspective. Methods: The primary literature search was conducted in Medline and Embase. Supplemental searches were conducted in the Cochrane NHS Economic Evaluation Database, the National Institute for Occupational Safety and Health database, the Ryerson International Labour, Occupational Safety and Health Index database, scans of reference lists and researcher's own literature database. Article selection was conducted independently by two researchers
\end{abstract}

K. Uegaki · M. W. van Tulder

Health Technology Assessment Unit, EMGO Institute for Health and Care Research, VU University Medical Center, Amsterdam, The Netherlands

K. Uegaki · M. C. de Bruijne $(\bowtie)$ · A. J. van der Beek ·

W. van Mechelen

Department of Public and Occupational Health, EMGO Institute for Health and Care Research, VU University Medical Center,

Van der Boechorststraat 7, 1081 BT Amsterdam,

The Netherlands

e-mail: mc.debruyne@vumc.nl

A. J. van der Beek . W. van Mechelen

Body@Work, Research Center Physical Activity, Work

and Health, TNO-VUmc, Amsterdam, The Netherlands

A. J. van der Beek

Research Center for Insurance Medicine AMC-UWV-VU

University Medical Center, Amsterdam,

The Netherlands

M. W. van Tulder

Institute of Health Sciences, Faculty of Earth and Life Sciences,

VU University, Amsterdam, The Netherlands based on title, keywords, and abstract, and if needed, full text. Differences were resolved by a consensus procedure. Articles were selected based on seven criteria addressing study population, type of intervention, comparative intervention, outcome, costs, language and perspective, respectively. Characteristics of the measurement and valuation of health-related productivity were extracted and analyzed descriptively. Results: A total of 34 studies were included. Costs of health-related productivity were estimated using (a combination of) data related to sick leave, compensated sick leave, light or modified duty or work presenteeism. Data were collected from different sources (e.g. administrative databases, worker self-report, supervisors) and by different methods (e.g. questionnaires, interviews). Valuation varied in terms of reported time units, composition and source of the corresponding price weights, and whether additional elements, such as replacement costs, were included. Conclusions: Methods for measuring and valuing health-related productivity vary widely, hindering comparability of results and decision-making. We provide suggestions for improvement.

Keywords Systematic review - Work - Methodology · Measurement · Valuation · Company

\section{Introduction}

Economic evaluations are a tool to help inform decision makers about how to best allocate limited resources. In occupational health, the interest in economic evaluations has steadily grown as stakeholders realize that resources for occupational health interventions are limited and health problems in the working population are paired with 
significant socioeconomic burden [1-3]. For example, the indirect cost of lost productive time by workers with depression has been estimated to be $\$ 44$ billion per year [4], and from a US survey of over 28,000 workers, productivity loss costs for companies due to workers' personal or family health problems was estimated $\$ 226$ billion per year [5]. In The Netherlands, companies are obligated to continue to pay $70-100 \%$ of the salary of employees during the first 2 years of sick leave, regardless of work-relatedness [6].

For results of economic evaluations to be informative, they must contain relevant and comparable data on costs and consequences. The choice of which costs and consequences are included in an economic evaluation is influenced by the perspective taken. Traditionally, a societal perspective is recommended, and in principle, all costs and consequences regardless of who pays or gains are included [7]. However, results from this broad approach may be difficult to apply for decision making at the local (workplace) level, warranting evaluations from a more specific stakeholder perspective, such as the company [8-10]. Indeed, in addition to growing interest, there is increasing awareness that company decision makers have a need for relevant and comparable information so that they can prioritize their budget in order to attain the greatest (health) gains for their workforce $[11,12]$.

In economic evaluations conducted from a company's perspective, one of the common ways to express the benefit of occupational health interventions is in terms of healthrelated productivity, which are translated into a monetary value and also referred to as indirect costs [13]. However, how this key variable is measured and valued may vary widely. Variability in costing methods used in cost-effectiveness analysis was recently reported by Adams et al. [14]. While most of the included studies did not include a measure of productivity, the authors identified three potential reasons for the observed variation in how productivity is handled: disagreements between existing economic evaluation guidelines on whether to include these costs, lack of practical guidance on how to comply with recommendations, and a simple omission of this cost in the guidelines themselves.

Variability in how health-related productivity is measured and valued can hinder the comparability of studies addressing the same health problem and across health problems, thereby limiting the utility of results for decision-making. In order to identify potential avenues for standardization, insight into the exact nature of the variability is needed. Thus, the objective of our systematic review was to map out the methods used to estimate indirect costs of health-related productivity in economic evaluations of occupational health interventions from a company's perspective.

\section{Methods}

\section{Study Design and Search Strategy}

A systematic review was conducted of economic evaluations from a company's perspective and based on primary research. We conducted our primary search in EMBASE.com, a database that combines all recorded journal entries of Medline from 1966 and Embase from 1974. An experienced search specialist from our institute developed the search strategy (Table 1), which covered the period from 1966 to April 10, 2007. Supplemental searches were conducted in the Cochrane NHS Economic Evaluation Database (NHS EED; search date April 13, 2007), the National Institute for Occupational Safety and Health database (NIOSHTIC-2; search date May 1, 2007), and the Ryerson International Labour, Occupational Safety and Health Index database (RILOSH; search date May 7, 2007). Additional articles were identified from reference lists and the researchers' own literature databases.

\section{Study Selection}

Two reviewers (KU and $\mathrm{MdB}$ ) independently determined the eligibility of studies on the basis of title, keywords and abstract, and if needed, a review of the full text. Differences in judgement were resolved through a consensus procedure. We selected studies based on seven criteria:

Table 1 Search strategy in EMBASE.com

\begin{tabular}{ll}
\hline Set & Search terms \\
\hline 1 & (economic-evaluation/exp) AND (employee/exp OR \\
& employee* OR employer/exp OR employer* OR \\
& industrial-worker/exp OR worker* OR work-site OR \\
& worksite OR workman-compensation/de OR \\
& workplace/de OR workplace OR work-capacity/de) \\
& Set 1 AND ([cochrane review]/lim OR [controlled \\
& clinical trial]/lim OR [systematic review]/lim OR \\
& comparative-study/de OR intermethod-comparison/de \\
& OR clinical-study/exp OR controlled-study/exp)
\end{tabular}

3 Set 1 AND (health-program/exp OR health-maintenanceorganization/exp OR occupational-health-service/exp OR preventive-health-service/exp)

4 Set 1 AND (productivity/exp OR absenteeism/exp OR return-to-work OR sick-leave OR job-performance/de OR work-resumption/de)

5 (Measur* OR valuing* OR valuation $\mathrm{OR}$ value* $\mathrm{OR}$ significance OR analys* OR estimat* OR assess* OR determinat* OR methodology/de OR accuracy/de)

$6 \quad$ (Set 3 OR set 4) AND set 5

Final set Set 2 OR set 6 
(1) the study population consisted of employed individuals $>16$ years; (2) the intervention in question was a workplace or primary care service, technology or program to prevent work disability; (3) the intervention was compared to an alternative; (4) an outcome that reflected a worker's health-related production capacity was measured and valued; (5) at minimum, costs of intervention-related resource use were included; (6) the study was reported in either Dutch or English; and (7) the economic analysis was conducted from a company's perspective. We excluded editorials, letters, articles describing the design of economic evaluations but not reporting any results, congress abstracts, reviews and modelling studies.

\section{Data Extraction}

To guide our data extraction procedure, we identified key aspects of measurement and valuation from existing guidelines and texts on economic evaluations [7, 15]. With respect to the measurement, we extracted data on the type of time losses that were used to quantify health-related productivity, data collection method and data source used. With regards to valuation, we extracted data on the time units and corresponding price weight used, and the composition and source of the price weight. In cases where information could not be found in the articles, we used the notation, "not specified". One researcher (KU) extracted the data and a second researcher (MdB) checked $10 \%$ for accuracy. No disagreements were identified. We synthesized the data descriptively.

\section{Applied Terminology}

We labelled the economic evaluations using the conceptual matrix proposed by Drummond et al. [7]. The type of economic evaluation is determined by the number of alternatives compared, if both costs and consequences are included, and how the consequences are expressed. In a cost-effectiveness analysis (CEA), the consequences are expressed in terms of a unit of effect, such as pain, function or symptom severity. A cost-utility analysis (CUA) is a variant in which the unit of effect is quality-adjusted life years. In a cost-benefit analysis (CBA), all health consequences (i.e. benefits due to improved health, future health care costs avoided and increased productive output due to improved health status) are translated into a monetary value using principles of willingness-to-pay [7]. The label, financial appraisal, was used to denote economic evaluations in which the costs and consequences of two or more alternatives are compared, but where the monetary consequences were limited to differences in health care use and/ or productivity valued using market prices.

\section{Results}

Study Selection

Our primary search in EMBASE.com generated 1,645 hits. We obtained an additional 166, 477 and 352 hits from our searches in NHS EED, NIOSHTIC-2 and RILOSH, respectively. From this total of 2,640 hits, 100 duplicates were removed, resulting in set of 2,540 articles. Of these, 2,422 were excluded based on title, keywords and abstract, and the full texts of the remaining 118 articles were assessed. Thirty studies were included based on our selection criteria. Thirty of the included studies were identified in EMBASE.com, and one from RILOSH. The searches in NHS EED and NIOSHTIC-2 did not result in any additional studies. Four additional articles were identified from the researchers' own literature database, resulting in a total of 34 studies for this review (Fig. 1).

\section{General Description of the Studies}

Physical health issues, such as back injury or pain, lacerations and musculoskeletal injuries or pain, were targeted in half of the studies [16-32]. Six studies evaluated health promotion/lifestyle and wellness interventions [33-38], and seven investigated the cost-effectiveness of influenza vaccines [39-45]. Mental health problems [46, 47] and migraine [48, 49] were addressed by two studies each. The studies originated in eight countries: USA [16, 18, 21, 23-26, 30-33, 36, 38, 39, 42, 46-49], The Netherlands [17, 20, 28, 35], Canada [19, 27, 37], Australia [34, 40, 45], Sweden [22, 29], Italy [41], Colombia [43], and Malaysia [44].

Thirty-two studies conducted a financial appraisal [1634, 36-48], and two studies performed both a financial appraisal and cost-effectiveness analysis [35, 49]. None of the studies conducted a cost-utility analysis. The lack of cost-utility analyses may be reflective of the fact that quality-adjusted life years may be considered less relevant or meaningful as an outcome for company decision makers compared to health-related productivity. On the cost-side of the economic evaluations, all studies included costs related to the programs in the question. Examples of program cost items were capital expenditures for equipment, labour costs for the staff to provide the interventions or run the programs, and operational, maintenance or material costs. Eight (24\%) studies included the time that employees take from work to undergo the intervention in the calculation of the program costs [16, 39-45]. Four studies (12\%) included data on health care use for the health problem, such as physician contacts, [20, 24, 39, 49]. Proper et al. [35] included productivity loss costs on the cost-side of the equation in their cost-effectiveness analysis. 
Fig. 1 Selection process scheme from search results to through to identification of the final set of articles
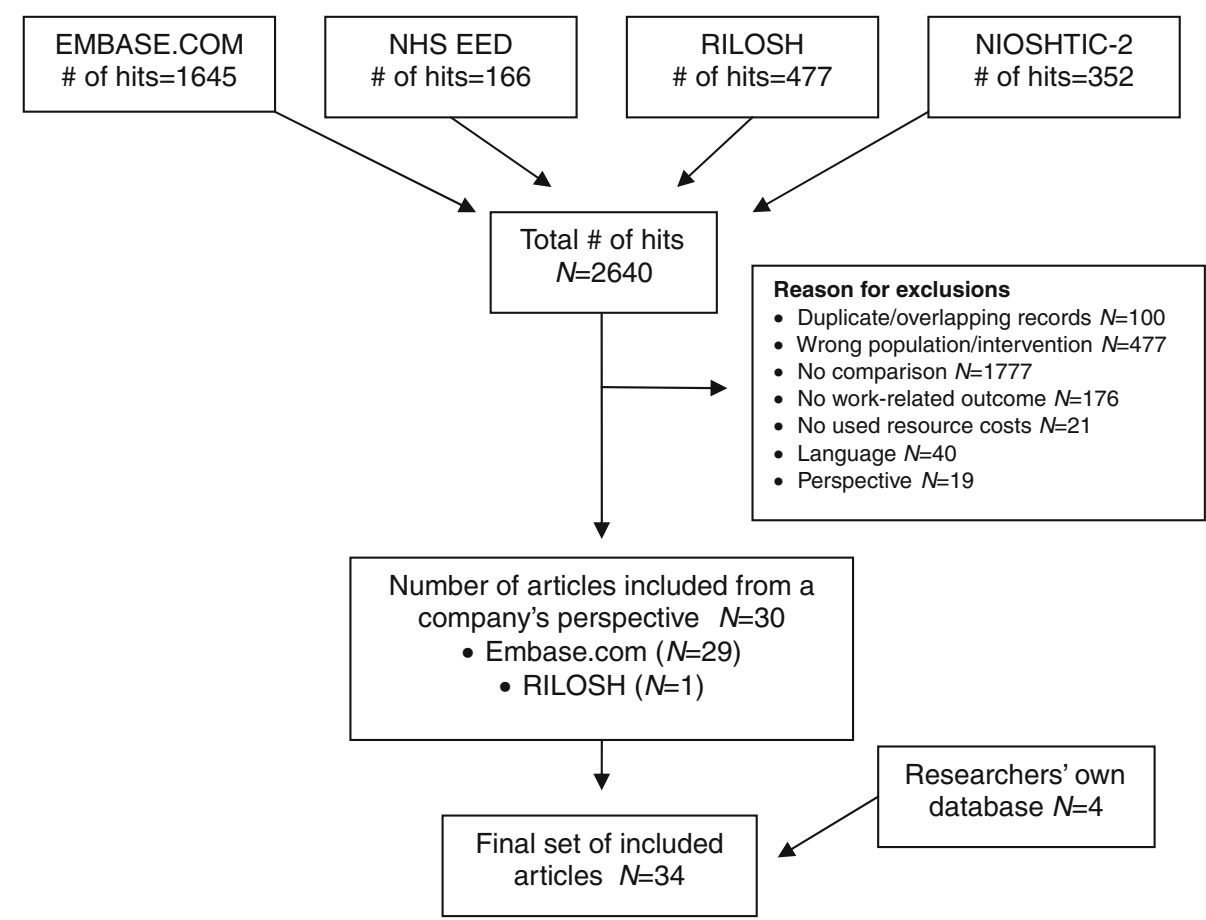

time work due to workers are at work in their original functions, however, perform their tasks less effectively due to their health problem. To facilitate further reporting, we used the following four labels to denote each proxy measure: (1) sick leave; (2) compensated sick leave; (3) limited or modified duty; and (4) work-presenteeism.

Absenteeism, whether sick leave or compensated sick leave, formed the basis of estimates of health-related productivity in all of the included studies. Four studies included both measures [25, 26, 32, 34]. Limited or modified duty and work-presenteeism were considered by four [20, 24, 25, 32] and six [17, 43, 44, 46, 48, 49] studies, respectively.

An overview of data sources for each proxy measure are presented in Table 2. Data on sick leave was collected either from administrative databases [20-22, 26, 28, 29, $33-36,38,41,45]$, self-report [17, 24, 31, 39, 40, 42-44, $46,48,49]$, report by others [16, 22, 25, 32, 47], or else not specified [37]. Company databases [20, 21, 26, 28, 33-36, $38,41,45]$ and non-standardized questionnaires [24, 31, $39,40,42-44,46]$ were the two most commonly used methods at 32 and $24 \%$, respectively. Of the ten studies using compensated sick leave to estimate health-related productivity, data was collected from either the company's own workers' compensation database [23, 25, 30, 32, 34], that of the insurer $[18,19,26,27]$, or not specified [16]. In terms of limited or modified duty, each of the four studies [20, 24, 25, 32] collected data in a different manner. Work-presenteeism was measured by either a non-standardized $[43,44,46]$ or standardized questionnaire [17, 48, 49]. 
Table 2 Data sources for each proxy measure of change in health-related productivity along with respective references

\begin{tabular}{|c|c|c|}
\hline Data source & Description & Number of studies [references] \\
\hline \multicolumn{3}{|l|}{ Sick leave } \\
\hline \multirow[t]{2}{*}{ Administrative database } & Company & $11[20,21,26,28,33-36,38,41,45]$ \\
\hline & National Insurance & $2[22,29]$ \\
\hline \multirow[t]{2}{*}{ Self-report } & $\begin{array}{l}\text { Non-standardized questionnaire } \\
\text { (written or telephone) }\end{array}$ & $8[24,31,39,40,42-44,46]$ \\
\hline & $\begin{array}{l}\text { Standardized questionnaire } \\
\text { (written or telephone) }\end{array}$ & $3[17,48,49]$ \\
\hline \multirow[t]{3}{*}{ Report by others } & Interview & $1[22]$ \\
\hline & OSHA $\log$ & $1[32]$ \\
\hline & Monthly injury report or log & $3[16,25,47]$ \\
\hline Not specified & $\begin{array}{l}\text { Method of data collection } \\
\text { not reported }\end{array}$ & $1[37]$ \\
\hline \multicolumn{3}{|l|}{ Compensated sick leave } \\
\hline \multirow[t]{2}{*}{ Administrative database } & Company & $5[23,25,30,32,34]$ \\
\hline & Workers compensation & $4[18,19,26,27]$ \\
\hline \multicolumn{3}{|l|}{ Limited or modified duty } \\
\hline Administrative database & Company & $1[20]$ \\
\hline Self-report & Non-standardized questionnaire & $1[24]$ \\
\hline \multirow[t]{2}{*}{ Report by others } & OSHA $\log$ & $1[32]$ \\
\hline & Monthly injury report or $\log$ & $1[25]$ \\
\hline \multicolumn{3}{|l|}{ Work-presenteeism } \\
\hline \multirow[t]{2}{*}{ Self report } & $\begin{array}{l}\text { Non-standardized questionnaire } \\
\text { (written or telephone) }\end{array}$ & $3[43,44,46]$ \\
\hline & $\begin{array}{l}\text { Standardized questionnaire } \\
\text { (written or telephone) }\end{array}$ & $3[17,48,49]$ \\
\hline
\end{tabular}

Valuing Health-Related Productivity

Studies that measured health-related productivity by sick leave, limited or modified duty or work-presenteeism calculated the costs by using the basic human capital formula: time lost units * price weight per time unit. Nine of the 10 studies using a measure of compensated sick leave determined the costs by the actual compensation payments. In these studies, aggregated totals were reported [16, 18, 19, 23, 25-27, 30, 32]. Monetary award payments from litigation were included by only one study [30]. The remaining study using a measure of compensated sick leave estimated costs via the human capital formula [34].

In the studies valuing sick leave by the human capital approach, five sources of variation in the methodology were observed: the time units used to quantify healthrelated productivity; the type of price weight used, the composition of the price weight, the source of the price weight, and additional elements in the calculation (Table 3). First, the time units used to quantify healthrelated productivity differed in terms of being either hours or days. While the majority of studies reported the number of work days, two additional variations were observed: accounting for partial days and quantifying calendar days.

Second, the corresponding price weights varied in terms of whether a worker-specific price weight was used, or a job-specific, job- and gender-specific, or generic price weight. Three studies did not provide information about the type of price weight $[26,37,44]$. Of the three studies that used a job-specific price weight, two used a mean for the job category [33, 41] and the remaining study did not include a specification [17]. Of the 16 studies that used a generic price weight, either the mean of the study or company population was used $[20,31,35,36,38,42,43$, 45 , 46], a national mean [49], a mean from the literature [29], the median of the study population [47], or not specified [28, 39].

Third, the composition of the price weight differed between studies in terms of whether or not secondary benefits were included in addition to the wage. Fifteen of the 28 studies included secondary benefits in their price weight, six did not and seven studies did not report this information. 
Table 3 Summary of the time units, price weight characteristics and additional elements used in the valuation of health-related productivity changes measured by sick leave

\begin{tabular}{|c|c|c|}
\hline $\begin{array}{l}\text { Valuation } \\
\text { component }\end{array}$ & Description & Number of studies [references] \\
\hline \multicolumn{3}{|l|}{ Time units } \\
\hline Hours & Changes in health-related productivity quantified in hours of work time missed & $5[17,33,45-47]$ \\
\hline \multirow[t]{4}{*}{ Days } & $\begin{array}{l}\text { Not otherwise specified: changes in health-related productivity quantified in days of } \\
\text { work time missed not otherwise specified. That is, no differentiation was made } \\
\text { between whole and partial days of time loss }\end{array}$ & $\begin{array}{l}20[21,22,24-26,28,29,31 \\
35-44,48,49]\end{array}$ \\
\hline & $\begin{array}{l}\text { Net or adjusted days: changes in health-related productivity quantified in which a } \\
\text { differentiation was made between whole and partial days of time loss }\end{array}$ & $3[16,20,34]$ \\
\hline & $\begin{array}{l}\text { Gross or unadjusted days: although partial days were measured, partial days were } \\
\text { quantified as whole days of time loss }\end{array}$ & $1[20]$ \\
\hline & $\begin{array}{l}\text { Calendar days: changes in health-related productivity quantified in terms of calendar } \\
\text { days. Note that price weight correspondingly reflected a calendar day as opposed to a } \\
\text { work day }\end{array}$ & $2[20,35]$ \\
\hline \multicolumn{3}{|l|}{ Price weights } \\
\hline Worker-specific & The specific salary or wage of a worker is used & $5[21,22,25,34,40]$ \\
\hline Job-specific & A uniform price weight is used for all workers in the same job function & $3[17,33,41]$ \\
\hline $\begin{array}{l}\text { Job- and gender- } \\
\text { specific }\end{array}$ & $\begin{array}{l}\text { A uniform price weight is used for all workers in the same job function but further } \\
\text { differentiated for gender }\end{array}$ & $1[48]$ \\
\hline Generic & One uniform price weight is used with no differentiation for job function, gender or age & $\begin{array}{l}16[16,20,24,28,29,31,35 \\
36,38,39,42,43,45-47,49]\end{array}$ \\
\hline Not specified & No description of the price weight was provided & $3[26,37,44]$ \\
\hline \multicolumn{3}{|c|}{ Composition of price weights } \\
\hline $\begin{array}{l}\text { Wage plus } \\
\text { benefits }\end{array}$ & The price weight encompasses wages plus secondary benefits & $\begin{array}{l}15[17,20,22,25,31,35 \\
\quad 40-47,49]\end{array}$ \\
\hline Wage only & The price weight consisted only of the wage rate & $6[16,26,28,34,38,48]$ \\
\hline Not specified & No description of the composition was provided & $7[21,24,29,33,36,37,39]$ \\
\hline \multicolumn{3}{|c|}{ Source of price weight } \\
\hline Company & Administrative databases & $\begin{array}{l}20[17,20-22,25,26,28,31 \\
\quad 33-36,38-43,45,47]\end{array}$ \\
\hline Literature & Published literature & $1[29]$ \\
\hline National & National databases such as the U.S. Bureau of Labor & $2[48,49]$ \\
\hline Participants & Participant self-report & $1[46]$ \\
\hline Not specified & Source not specified & $4[16,24,37,44]$ \\
\hline \multicolumn{3}{|l|}{ Additional elements } \\
\hline Elasticity & This represents the less than proportional decrease in productivity loss to worked hours & $1[35]$ \\
\hline $\begin{array}{l}\text { Loss of operating } \\
\text { income }\end{array}$ & $\begin{array}{l}\text { This represents the average contribution to the company's global productivity that is } \\
\text { lost when a worker is absent due to a health problem. This was determined from } \\
\text { company data }\end{array}$ & $3[40,43,44]$ \\
\hline Turnover & $\begin{array}{l}\text { This represents the costs associated with having to recruit, hire and train a new } \\
\text { employee. It should be noted that there was variation in how these costs were } \\
\text { estimated }\end{array}$ & $2[34,47]$ \\
\hline Replacement & $\begin{array}{l}\text { This represents the costs related to replacing a worker temporarily. The calculation } \\
\text { method of these costs varied or not specified in each study }\end{array}$ & $3[33,40,44]$ \\
\hline Indirect costs & $\begin{array}{l}\text { A general rule of thumb of } 2 \times \text { the direct savings were used to account for savings from } \\
\text { "indirect" spill over effects such as overtime, turnover, recruiting and training, } \\
\text { increased employee morale and/or non-worker's compensation related absenteeism }\end{array}$ & $2[19,27]$ \\
\hline Wage multipliers & $\begin{array}{l}\text { These represent weights based on the theoretical model of Pauly et al. that the } \\
\text { productivity loss costs of a worker's complete absence is more than full wage plus } \\
\text { benefits per day worked }\end{array}$ & $1[46]$ \\
\hline
\end{tabular}


Fourth, in a majority (20 of 28 ) of the studies, the price weight was obtained from the company. Published literature, a national database and participant self-report were the sources of the cost-prices in respectively, one, two and one study. Four studies did not report the source of their price weight.

Last, the valuation of sick leave-based productivity costs differed among the studies in terms of whether or not additional elements were included in the calculation, and if included, the type of additional element. Of the 11 studies that included additional elements, one study [35] adjusted the estimation of sick leave-based productivity costs based on the assumption of elasticity, which states that the productivity loss is less than proportional to the time lost. In contrast, the additional elements considered in the remaining 10 studies represent extra costs, indicating that productivity loss costs were more than that based on sick leave time alone $[19,27,33,34,40,43,44$, 46, 47].

Similar sources of variation were observed in the valuation methodology of limited or modified duty and work presenteeism (Table 4).

Table 4 Summary of the time units, price weight characteristics and additional elements used in the valuation of health-related productivity changes measured by limited or modified duty and work-presenteeism

\begin{tabular}{|c|c|c|c|}
\hline \multirow[t]{2}{*}{ Valuation component } & \multirow[t]{2}{*}{ Description } & \multicolumn{2}{|c|}{ Number of studies [References] } \\
\hline & & $\begin{array}{l}\text { Limited or } \\
\text { modified duty }\end{array}$ & Work-presenteeism \\
\hline \multicolumn{4}{|l|}{ Time units } \\
\hline Days & Days & $3[24,25,32]$ & $4[17,43,48,49]$ \\
\hline Not specified & Units not specified & & $2[44,46]$ \\
\hline \multicolumn{4}{|l|}{ Price weights } \\
\hline Worker-specific & The specific salary or wage of a worker is used & $1[25]$ & \\
\hline Job-specific & $\begin{array}{l}\text { A uniform price weight is used for all workers in the } \\
\text { same job function }\end{array}$ & & $1[17]$ \\
\hline Job- and gender-specific & $\begin{array}{l}\text { A uniform price weight is used for all workers in the } \\
\text { same job function but further differentiated for gender }\end{array}$ & & $1[48]$ \\
\hline Generic & $\begin{array}{l}\text { One uniform price weight is used with no differentiation } \\
\text { for job function, gender or age }\end{array}$ & $2[24,32]$ & $3[43,46,49]$ \\
\hline Not specified & No description of the price weight was provided & & $1[44]$ \\
\hline \multicolumn{4}{|l|}{ Composition of price weights } \\
\hline Wage plus benefits & $\begin{array}{l}\text { The price weight encompasses wages plus secondary } \\
\text { benefits. Note that we interpreted the term "salary" to } \\
\text { mean wage plus benefits }\end{array}$ & $1[25]$ & $5[17,25,43,44,46,49]$ \\
\hline Wage only & The price weight consisted only of the wage rate & & $1[48]$ \\
\hline Not specified & No description of the composition was provided & $2[24,32]$ & \\
\hline \multicolumn{4}{|l|}{ Source of price weight } \\
\hline Company & Administrative databases & $1[32]$ & $3[17,43,44]$ \\
\hline National & National databases such as the U.S. Bureau of Labor & & $2[48,49]$ \\
\hline Participants & Participant self-report & $1[25]$ & $1[46]$ \\
\hline Not specified & Source not specified & $1[24]$ & \\
\hline \multicolumn{4}{|l|}{ Additional elements } \\
\hline Loss of operating income & $\begin{array}{l}\text { This represents the average contribution to the } \\
\text { company's global productivity that is lost when a } \\
\text { worker functions less efficiently due to a health } \\
\text { problem. This was determined from company data }\end{array}$ & & $2[43,44]$ \\
\hline Wage multipliers & $\begin{array}{l}\text { These represent weights based on the theoretical model } \\
\text { of Pauly et al. that the productivity loss costs of a } \\
\text { worker due to work-presenteeism is more than its full } \\
\text { wage equivalent }\end{array}$ & & $1[46]$ \\
\hline
\end{tabular}




\section{Discussion}

We conducted a systematic review to gain insight into the variation in how the health-related productivity is measured and valued in economic evaluations from a company's perspective. Thirty-four studies were included. With respect to measurement, we identified considerable variation in the type and number of proxy measures used as well as the data collection methods for each specific measure. With regards to valuation, we observed variation in terms of the reported time units, type, composition and source of the unit price weights, and whether additional elements, such as replacement costs, were included.

To our knowledge, this is the first study to systematically evaluate the variation in how health-related productivity were measured and valued in economic evaluations from a company's perspective. Although we searched four databases as well as the reference lists of included studies and our own database, we cannot guarantee that we captured all eligible studies. We do not believe, however, that additional studies would significantly alter our findings or recommendations. Also, given that our searches in NHS EED and NIOSHTIC-2 did not result in any extra studies, we conclude that the risk of missed studies is small.

In absence of objective productivity measures, estimates have been based on lost work time due sick leave. A gold standard for collecting sick leave data does not exist. Both databases and questionnaires have their advantages and disadvantages, which need to be weighed per research question. However, using insurance databases have a particular disadvantage in that the data reflects what has been compensated; what has been compensated does not necessarily equate to the actual time a worker has been unable to work. If lost work time is collected from insurancerelated databases, the amount of time lost during the waiting period before insurance coverage actually comes into effect also needed to be measured [50]. Productivity loss related to sick leave should be supplemented by the productivity loss due to decreased work performance to avoid underestimation [51]. For comparability, a standardized questionnaire should be used. In the past decade and a half, a number have been developed for this purpose [52-54]. The fact that very few studies in the review used a standardized questionnaire may be due to the inevitable time lag in the knowledge transfer process, even in research, between new developments and implementation. Also, time and costs associated with using a standardized questionnaires may hamper their application.

Valuating health-related productivity into a financial metric makes this variable more interpretable for company managers. In an economic evaluation, the purpose is to determine if one intervention is more cost-effective than another. The productivity loss costs are a main cost driver.
Therefore, it is critical that time units are valued properly. In particular, one common price weight should be used for all subjects. This is because the difference in the effect of the intervention is on the difference in change in productivity. The use of worker-specific wages can distort the actual difference [55]. Currently, there is no gold standard for valuing health-related productivity. As such, key assumptions of different methods should be tested in a sensitivity analysis.

A certain extent of the variation may reflect the social context in which the study takes place. This social context encompasses political, cultural, legislative and other aspects such as the type of compensation system, legislation on workers' rights for accommodation in the workplace, or attitudes toward the ability of persons with health conditions or disability to stay successfully employed. Studies conducted in countries that have a workers' compensation system (e.g. Canada and United States) often used data from workers' compensation databases. In such jurisdictions, there is a differentiation between work-related and non-work related time loss. In contrast, in countries such as The Netherlands, such a differentiation does not exist and all work time loss due to a health problem is measured as sick leave. Given the variation arising from context, it is not realistic to think that one exact method for measurement and valuation can be prescribed. We also note that social context may influence the interventions themselves, that is, interventions may be context specific, restricting the extent to which one can learn from crosscountry evidence as well as the results of this current review. Nevertheless, a future endeavour for the field of occupational health should be to establish best practice guidelines for economic evaluations of occupational health interventions. These guidelines should provide explicit recommendations for reporting key aspects of methodology underlying the measurement and valuation of health-related productivity. Such transparency and improvements in reporting will simplify the process of determining the comparability of studies. In addition, it will also facilitate the transferability of results.

In sum, the variation in the measurement and valuation methods to determine the indirect costs of health-related productivity limits comparability of economic evaluations for the same health problem as well as between health problems. To help improve the comparability and interpretability of economic evaluations of occupational health interventions from a company's perspective, a future endeavour may be to establish an international task force to develop standardized guidelines. In the meantime, the following five points deserve attention:

(i) Use of standardized questionnaires to measure healthrelated productivity. 
(ii) Explicit presentation of measurement methods and time units of health-related productivity. This will mean disaggregating the amount of work loss from administrative databases. This may be a challenge when using workers' compensation data, however, just the costs can be misleading as the pay-outs are dependent on the local jurisdictions and insurance companies.

(iii) Explicit presentation of the composition and source of corresponding price weights used to value healthrelated productivity.

(iv) Explicit presentation of the additional effects included in the analysis as well as the rational for including these effects.

(v) Clear description of the socio-political context in which the study takes place. This is so that readers from other jurisdictions can see how the distribution of burden is similar or different to theirs.

\section{Conclusion}

The methods to measure and value health-related productivity vary widely among economic evaluations of occupational health interventions conducted from a company's perspective. This hinders the comparability and usability of results by occupational health professionals and company decision makers in order to inform decisions about $\mathrm{OH}$ interventions. We provide suggestions for improvement in future studies.

Acknowledgments The authors extend their gratitude to Ingrid Riphagen for her time and expertise in developing and running the primary search strategy in Embase.com. The authors also thank Stefan IJmker for his assistance with conducting the literature search in RILOSH.

Open Access This article is distributed under the terms of the Creative Commons Attribution Noncommercial License which permits any noncommercial use, distribution, and reproduction in any medium, provided the original author(s) and source are credited.

\section{References}

1. Burdorf A. Economic evaluation in occupational health-its goals, challenges, and opportunities. Scand J Work Environ Health. 2007;33:161-4.

2. Leigh JP. Expanding research on the economics of occupational health. Scand J Work Environ Health. 2006;32:1-4.

3. van der Beek AJ, Frings-Dresen MH, van Dijk FJ, Houtman IL. Priorities in occupational health research: a Delphi study in The Netherlands. Occup Environ Med. 1997;54:504-10.

4. Stewart WF, Ricci JA, Chee E, Morganstein D, Lipton R. Lost productive time and cost due to common pain conditions in the US workforce. JAMA. 2003;290:2443-54.
5. Stewart WF, Ricci JA, Chee E, Morganstein D. Lost productive work time costs from health conditions in the United States: results from the American Productivity Audit. J Occup Environ Med. 2003;45:1234-46.

6. Ministerie van Sociale Zaken en Werkgelegenheid (SZW). Wet verlenging loondoorbetalingsverplichten bij ziekte [Extension of sick leave benefits law]. URL: http://www.werkennaarvermogen.nl. 2006.

7. Drummond MF, Sculpher MJ, Torrance GW, O'Brien BJ, Stoddart GL. Methods for the economic evaluation of health care programmes. 3rd ed. ed. Oxford: Oxford University Press; 2005.

8. Berger ML, Murray JF, Xu J, Pauly M. Alternative valuations of work loss and productivity. J Occup Environ Med. 2001;43: $18-24$.

9. Brouwer WB, van Exel NJ, Baltussen RM, Rutten FF. A dollar is a dollar is a dollar-or is it? Value Health. 2006;9:341-7.

10. Young AE, Wasiak R, Roessler RT, McPherson KM, Anema JR, van Poppel MN. Return-to-work outcomes following work disability: stakeholder motivations, interests and concerns. J Occup Rehabil. 2005;15:543-56.

11. Tompa E, Dolinschi R, de Oliveira C. Practice and potential of economic evaluation of workplace-based interventions for occupational health and safety. J Occup Rehabil. 2006;16:367-92.

12. Mayne TJ, Howard K, Brandt-Rauf PW. Measuring and evaluating the effects of disease on workplace productivity. J Occup Environ Med. 2004;46:S1-2.

13. Greenberg PE, Birnbaum HG, Kessler RC, Morgan M, Stang P. Impact of illness and its treatment on workplace costs: regulatory and measurement issues. J Occup Environ Med. 2001;43: $56-63$.

14. Adam T, Koopmanschap MA, Evans DB. Cost-effectiveness analysis: can we reduce variability in costing methods? Int $\mathrm{J}$ Technol Assess Health Care. 2003;19:407-20.

15. Evers S, Goossens M, de Vet H, van Tulder M, Ament A. Criteria list for assessment of methodological quality of economic evaluations: consensus on health economic criteria. Int $\mathrm{J}$ Technol Assess Health Care. 2005;21:240-5.

16. Banco L, Lapidus G, Monopoli J, Zavoski R. The safe teen work project: a study to reduce cutting injuries among young and inexperienced workers. Am J Ind Med. 1997;31:619-22.

17. Burdorf A, Windhorst $\mathrm{J}$, van der Beek AJ, van der Molen $\mathrm{H}$, Meerding WJ. De kosten en baten van nieuwe arbeidsmiddelen bij straatmaken en vloerleggen [The costs and benefits of ergonomic equipment for street making and laying cement flooring]. Tijdschrift van Toegepast Arbowetenschap. 2005;1:3-11.

18. Collins JW, Wolf L, Bell J, Evanoff B. An evaluation of a "best practices" musculoskeletal injury prevention program in nursing homes. Injury Prev. 2004;10:206-11.

19. Engst C, Chhokar R, Miller A, Tate RB, Yassi A. Effectiveness of overhead lifting devices in reducing the risk of injury to care staff in extended care facilities. Ergonomics. 2005;48:187-99.

20. Hlobil H, Uegaki K, Staal JB, de Bruyne MC, Smid T, van Mechelen W. Substantial sick-leave costs savings due to a graded activity intervention for workers with non-specific sub-acute low back pain. Eur Spine J. 2007;16:919-24.

21. Hochanadel CD, Conrad DE. Evolution of an on-site industrial physical therapy program. J Occup Med. 1993;35:1011-6.

22. Landstad BJ, Gelin G, Malmquist C, Vinberg S. A statistical human resources costing and accounting model for analysing the economic effects of an intervention at a workplace. Ergonomics. 2002;45:764-87.

23. Melhorn JM, Wilkinson L, Gardner P, Horst WD, Silkey B. An outcomes study of an occupational medicine intervention program for the reduction of musculoskeletal disorders and cumulative trauma disorders in the workplace. J Occup Environ Med. 1999;41:833-46. 
24. Mitchell LV, Lawler FH, Bowen D, Mote W, Asundi P, Purswell J. Effectiveness and cost-effectiveness of employer-issued back belts in areas of high risk for back injury. J Occup Med. 1994;36: 90-4.

25. Nelson A, Matz M, Chen F, Siddharthan K, Lloyd J, Fragala G. Development and evaluation of a multifaceted ergonomics program to prevent injuries associated with patient handling tasks. Int J Nurs Stud. 2006;43:717-33.

26. Shi L. A cost-benefit analysis of a California county's back injury prevention program. Public Health Rep. 1993;108:204-11.

27. Spiegel J, Yassi A, Ronald LA, Tate RB, Hacking P, Colby T. Implementing a resident lifting system in an extended care hospital. Demonstrating cost-benefit. AAOHN J. 2002;50:128-34.

28. Versloot JM, Rozeman A, Van Son AM, Van Akkerveeken PF. The cost-effectiveness of a back school program in industry: a longitudinal controlled field study. Spine. 1992;17:22-7.

29. Linton SJ, Bradley LA. An 18-month follow-up of a secondary prevention program for back pain: HELP and hindrance factors related to outcome maintenance. Clin J Pain. 1992;8:227-36.

30. Littleton M. Cost-effectiveness of a prework screening program for the University of Illinois at Chicago physical plant. Work. 2003;21:243-50.

31. Alexander RW, Brennan JC, Maida AS, Walker RJ. The value of preplacement medical examinations for nonhazardous light duty work. J Occup Med. 1977;19:107-12.

32. Franzblau A, Werner RA, Yihan J. Preplacement nerve testing for carpal tunnel syndrome: is it cost effective? J Occup Environ Med. 2004;46:714-9.

33. Aldana SG, Merrill RM, Price K, Hardy A, Hager R. Financial impact of a comprehensive multisite workplace health promotion program. Prev Med. 2005;40:131-7.

34. Blaze-Temple D, Howat P. Cost benefit of an Australian EAP. Employee Assist Q. 1997;12:1-24.

35. Proper KI, de Bruyne MC, Hildebrandt VH, van der Beek AJ, Meerding WJ, van Mechelen W. Costs, benefits and effectiveness of worksite physical activity counseling from the employer's perspective. Scand J Work Environ Health. 2004;30:36-46.

36. Schultz AB, Lu C, Barnett TE, Yen LTC, McDonald T, Hirschland D, et al. Influence of participation in a worksite health-promotion program on disability days. J Occup Environ Med. 2002;44:776-80.

37. Shephard RJ. Long term impact of a fitness programme-the Canada Life Study. Ann Acad Med Singapore. 1992;21:63-8.

38. Skisak CM, Bhojani F, Tsai SP. Impact of a disability management program on employee productivity in a petrochemical company. J Occup Environ Med. 2006;48:497-504.

39. Campbell DS, Rumley MH. Cost-effectiveness of the influenza vaccine in a healthy, working-age population. J Occup Environ Med. 1997;39:408-14.

40. Cohen P, Darling C, Hampson A, Downs K, Tasset-Tisseau A. Influenza vaccination in an occupational setting: effectiveness and cost-benefit study. J Occup Health Safety Aust NZ. 2003;19: 167-82.

41. Colombo GL, Ferro A, Vinci M, Zordan M, Serra G. Cost-benefit analysis of influenza vaccination in a public healthcare unit. Ther Clin Risk Manage. 2006;2:219-26.

42. Dille JH. A worksite influenza immunization program: impact on lost work days, health care utilization, and health care spending. AAOHN J. 1999;47:301-9.

43. Morales A, Martinez MM, Tasset-Tisseau A, Rey E, Baron-Papillon F, Follet A. Costs and benefits of influenza vaccination and work productivity in a Colombian company from the employer's perspective. Value Health. 2004;7:433-41.

44. Samad AH, Usul MHBH, Zakaria D, Ismail R, Tasset-Tisseau A, Baron-Papillon $\mathrm{F}$, et al. Workplace vaccination against influenza in Malaysia: does the employer benefit? J Occup Health. 2006;48: $1-10$.

45. Thomson P, Cuddeford G, Mitchell P. Hospital staff absenteeism following an influenza immunisation program. J Occup Health Saf Aust New Zealand. 1999;15:231-42.

46. Lo Sasso AT, Rost K, Beck A. Modeling the impact of enhanced depression treatment on workplace functioning and costs: a costbenefit approach. Med Care. 2006;44:352-8.

47. Smoot SL, Gonzales JL. Cost-effective communication skills training for state hospital employees. Psychiatr Serv. 1995;46: 819-22.

48. Legg RF, Sclar DA, Nemec NL, Tarnai J, Mackowiak JI. Cost benefit of sumatriptan to an employer. J Occup Environ Med. 1997;39:652-7.

49. Lofland JH, Kim SS, Batenhorst AS, Johnson NE, Chatterton ML, Cady RK, et al. Cost-effectiveness and cost-benefit of sumatriptan in patients with migraine. Mayo Clin Proc. 2001;76:1093-101.

50. Reville RT, Bhattacharya J, Sager Weinstein LR. New methods and data sources for measuring economic consequences of workplace injuries. Am J Ind Med. 2001;40:452-63.

51. Brouwer WB, van Exel NJ, Koopmanschap MA, Rutten FF. Productivity costs before and after absence from work: as important as common? Health Policy. 2002;61:173-87.

52. Amick BC III, Lerner D, Rogers WH, Rooney T, Katz JN. A review of health-related work outcome measures and their uses, and recommended measures. Spine. 2000;25:3152-60.

53. Kessler RC, Barber C, Beck A, Berglund P, Cleary PD, McKenas $D$, et al. The World Health Organization Health and Work Performance Questionnaire (HPQ). J Occup Environ Med. 2003;45: 156-74.

54. Koopmanschap MA. PRODISQ: a modular questionnaire on productivity and disease for economic evaluation studies. Expert Rev Pharmacoecon Outcomes Res. 2005;5:23-8.

55. Oostenbrink JB, Bouwmans CAM, Koopmanschap MA, Rutten FFH. Dutch manual for costing: methods and standard costs for economic evaluations in health care. Diemen: Health Insurance Council (CVZ) 2004. 